\title{
Proteinuria Is Unrelated to the Extent of Acute Acetaminophen Overdose: A Prospective Clinical Study
}

\author{
Suzanne Benhalim, MB, Gillian E. Leggett, MB, Helen Jamie, W. Stephen Waring, PhD, FRCP
}

Scottish Poisons Information Bureau, Royal Infirmary of Edinburgh, UK

\begin{abstract}
Background: Acute renal failure is a recognized complication of acute acetaminophen overdose. Its detection depends on rising creatinine concentrations, which is an insensitive method. The present study examined whether proteinuria might correspond with the extent of acute acetaminophen exposure as a possible early marker of renal effects.

Methods: A prospective case-control study included patients attending the emergency department within 24 hours of acetaminophen ingestion. A urine specimen was collected within 12 hours of hospital attendance for creatinine, albumin, and protein determination. Equivalent 4-hour acetaminophen concentrations were used to indicate drug exposure: mild if $<100 \mathrm{~g} / \mathrm{L}$ ( $<662$ $\mathrm{mmol} / \mathrm{L})$, moderate if $100-200 \mathrm{~g} / \mathrm{L}(662-1323 \mathrm{mmol} / \mathrm{L})$, or severe if $>200 \mathrm{~g} / \mathrm{L}(>1323 \mathrm{mmol} / \mathrm{L})$. Data are presented as median (interquartile range) and groups compared using Mann Whitney and chi-square tests.

Results: Seventy patients were studied (17 men, 53 women), age 37 years (23-45 years). The stated acetaminophen dose was $15 \mathrm{~g}$ (8-20 g), and interval between ingestion and presentation was 4.6 hours (4.1-7.9 hours). Urinary albumin concentrations were $8 \mathrm{mg} / \mathrm{L}$ (0-12 mg/L) in the mild group, $12 \mathrm{mg} / \mathrm{L}(5-25 \mathrm{mg} / \mathrm{L})$ in the moderate group, and $11 \mathrm{mg} / \mathrm{L}$ (6-22 mg/L) in the severe group. Total protein concentrations were $90 \mathrm{mg} / \mathrm{L}$ (50-183 mg/L), $70 \mathrm{mg} / \mathrm{L}$ (40 to $130 \mathrm{mg} / \mathrm{L}$ ), and $110 \mathrm{mg} / \mathrm{L}$ (75-205 mg/L), respectively. The proportions of patients who had urine albumin:creatinine ratio $>3 \mathrm{mg} / \mathrm{mmol}$ were $20.8 \%, 23.5 \%$, and $21.2 \%$, respectively. None of the patients developed acute renal failure.

Conclusions: No relationship was found between the extent of acute acetaminophen exposure and proteinuria. Further work is required to examine whether urinary protein excretion is altered in patients who subsequently develop acute renal failure following acetaminophen overdose.
\end{abstract}

\section{INTRODUCTION}

Acute renal failure is a recognized complication of acetaminophen overdose, but has received comparatively little attention. Whereas the occurrence of fulminant hepatic failure is well characterized, there are few reliable data concerning the incidence of acetaminophen-induced nephrotoxicity. Acute renal failure occurred in 13 patients $(0.6 \%)$ in a series of 2068 young adults attending the emergency department (ED) after acetaminophen overdose [1]. Elsewhere, renal failure was reported in 4 out of 45 adolescents
(8.9\%) after acute acetaminophen overdose [2]. Acetaminophen nephrotoxicity is associated with oliguria in approximately two thirds of patients, and renal replacement therapy is needed in up to one third [3]. The clinical features, investigations, and renal biopsy findings are consistent with drug-induced acute tubular necrosis [4]. Predisposing factors are concomitant ingestion of nephrotoxic drugs, dehydration, staggered ingestion, preexisting renal insufficiency, and chronic excess ethanol consumption $[5,6]$.

A rapid rise in serum transaminase activity allows early detection of hepatotoxicity, and peak activity typically occurs at around

Keywords: acetaminophen, albumin:creatinine ratio, creatinine, proteinuria, renal failure

Acknowledgments: This work was supported by a Medical Fellowship from GlaxoSmithKline UK Limited (A0704117). We gratefully acknowledge the nursing staff of the Toxicology Unit of the Royal Infirmary of Edinburgh for assistance with urine sample collection. Notes:

Corresponding Author: W. S. Waring, Scottish Poisons Information Bureau, Royal Infirmary of Edinburgh, 51 Little France Crescent,Edinburgh, EH16 4TJ, UK. Email: s.waring@ed.ac.uk 
48 hours after ingestion. In contrast, acute renal failure is defined by rising serum creatinine concentrations and does not normally become evident until 2-5 days after acetaminophen overdose. Peak serum creatinine concentrations typically occur at around 6-9 days after ingestion, and recover slowly thereafter $[1,3,7]$. Irrespective of etiology, serum creatinine concentrations are of limited value for detecting an early acute decline in kidney function [8]. A variety of indices have been examined as potential early markers of acute renal failure: serum cystatin $\mathrm{C}$ and urine concentrations of neutrophil gelatinase-associated lipocalin, interleukin-18, glutathioneS-transferase-pi, and gamma-glutathione-S-transferase [9]. There are insufficient data to support the routine use of any of these after acetaminophen overdose. Acetaminophen is associated with increased urinary $\beta$ - 2 microglobin concentrations and $\gamma$-glutamyl transferase activity, and these predict nephrotoxicity in some patients $[10,11]$. In animals, acetaminophen-induced acute tubular injury is associated with excess urinary albumin excretion [12]. If a similar mechanism were operating in patients after acetaminophen overdose, then proteinuria could provide an early indication of renal drug effect, and might allow identification of those at greatest risk of nephrotoxicity. Laboratory assays are sufficiently sensitive to detect abnormally high urinary protein excretion in the microalbuminuria range (30-300 $\mathrm{mg} / \mathrm{L})$.

The present study sought to examine whether a relationship exists between the extent of drug exposure after acetaminophen overdose, indicated by the equivalent 4 -hour serum acetaminophen concentration, and urinary protein excretion.

\section{METHODS}

\section{Patients}

The study group was identified from the Toxicology Unit between September 2007 and January 2008. Inclusion criteria were men and women, age 16-60 years, and presentation to hospital within 24 hours of deliberate acetaminophen overdose. Exclusion criteria were co-ingestion of any potentially nephrotoxic drug (aspirin, diuretic, nonsteroidal anti-inflammatory agent, angiotensin converting enzyme inhibitor, angiotensin receptor blocker), chronic renal impairment, diabetes mellitus, and pregnancy (determined using a urinary human chorionic gonadotropin assay). Routine practice in the UK is to administer a standardized 20-hour intravenous acetylcysteine regimen to patients at highest risk of hepatotoxicity based on the extent of acetaminophen exposure [13]. Equivalent 4-hour acetaminophen concentrations were used to define minor exposure $<100$ $\mathrm{g} / \mathrm{L}(<662 \mathrm{mmol} / \mathrm{L})$, moderate exposure 100-200 g/L (662-1323 $\mathrm{mmol} / \mathrm{L})$, and severe $>200 \mathrm{~g} / \mathrm{L}(>1323 \mathrm{mmol} / \mathrm{L})$. Acetylcysteine is normally administered after severe and moderate exposure if additional risk factors for hepatotoxicity are present, i.e., chronic ethanol excess; use of enzyme-inducing drugs (carbamazepine, phenobarbital, phenytoin, rifampicin, St. John's wort); chronic liver disease; or malnutrition. Renal function is determined from serum creatinine concentration at presentation to hospital and after acetylcysteine administration.

\section{Sample Collection and Urinalyses}

A data collection sheet was used to record patient age, gender, date and time of overdose, stated acetaminophen dose, and serum acetaminophen concentration. The history of ingestion was based on patient self-reporting and supported, when available, with empty drug packaging and witness accounts. A midstream urine sample was collected between 4 hours after ingestion up to 12 hours after presentation to hospital. Urine creatinine, albumin, and total protein concentrations were determined by the local accredited reference laboratory using an immuno-turbidimetry method. Absorbance is proportional to aggregation between albumin and standard antihuman antibody, and the range of albumin concentrations is $10-1000 \mathrm{mg} / \mathrm{L}$. Near-patient testing was performed using Microalbustix reagent strips (Bayer Diagnostics Ltd., Bridgend, UK). These allow semiquantitative estimations of albumin $(10,30,80$, and $150 \mathrm{mg} / \mathrm{L})$ and creatinine concentrations $(0.9,4.4,8.8,17.7$, and $26.5 \mathrm{mmol} / \mathrm{L})$, and albumin:creatinine ratios are discerned as normal or abnormal by reference to a table provided by the manufacturer [14].

\section{Data Analyses}

The primary outcome variables were urine creatinine concentration, albumin concentration, albumin:creatinine ratio, and total protein concentration. Abnormal values defined by the local reference laboratory were albumin $>20 \mathrm{mg} / \mathrm{L}$, total protein $>150$ $\mathrm{mg} / \mathrm{L}$, and albumin:creatinine ratio $>3 \mathrm{mg} / \mathrm{mmol}$. Equivalent 4-hour acetaminophen concentrations $\left(\mathrm{C}_{4}\right)$ were obtained from the formula $C_{t}=C_{4} \times 2 \times e^{-(0.693 / 4) t}$, where $C_{t}$ is the acetaminophen concentration at interval after ingestion in hours ( $t$ ) [15]. The primary outcome variables were presented as median (interquartile range) for each exposure group (minor, moderate, and severe). Comparisons were made between groups by Mann Whitney tests and Cochrane Armitage trend tests, and analytical methods were compared using Yates' corrected chi-square proportional tests. The relationship between acetaminophen exposure and urinary protein excretion was examined using a receiver operating characteristic. All analyses were performed using MedCalc software v.9.1.0.1 (MedCalc, Mariakerke, Belgium), and $p$-values $<0.05$ were accepted as statistically significant in all cases.

\section{RESULTS}

Seventy patients were studied (53 women), and median (interquartile range) age was 37 years (23-45 years). The stated acetaminophen dose was $15 \mathrm{~g}$ (8-20 g), and interval between ingestion and determination of serum concentrations was 4.6 hours (4.1-7.9 hours). Four patients presented to hospital within 24 hours of staggered acetaminophen ingestion and 66 patients presented after acute single ingestion; the extent of acetaminophen exposure was minor in 27 (40.9\%), moderate in 19 (28.8\%), and severe in 20 (30.3\%). Ethanol was co-ingested in $39(55.7 \%)$ patients, and other drugs were co-ingested in 29 (41.4\%); coingested drugs were selective serotonin reuptake inhibitors (10), opiates (7), antipsychotics (5), antiepileptics (2), metformin (2), 
Table 1: Characteristics of Patients as Median (Interquartile Range)

\begin{tabular}{|c|c|c|c|c|}
\hline \multirow{2}{*}{$\begin{array}{l}\text { Acetaminophen } \\
\text { exposure: }\end{array}$} & \multicolumn{3}{|c|}{ Acute single ingestion } & \multirow{2}{*}{$\begin{array}{c}\text { Staggered } \\
\text { overdose } n=4\end{array}$} \\
\hline & Minor $\mathbf{n}=\mathbf{2 7}$ & Moderate $\mathbf{n}=19$ & Severe $\mathbf{n}=\mathbf{2 0}$ & \\
\hline Age $(y)$ & $33(23-40)$ & $42(27-51)$ & $40(20-47)$ & $38(26-47)$ \\
\hline Female & $23(82.1 \%)$ & $9(50.0 \%)$ & $18(90.0 \%)$ & $3(75.0 \%)$ \\
\hline Dose $(g)$ & $8(7$ to 16$)$ & $13(9$ to 20$)$ & $18(15 \text { to } 28)^{*}$ & $12(-) \ddagger$ \\
\hline Acetaminophen (mg/L) & $37(21-76)$ & $112(94-145)^{*}$ & $147(62-225)^{*}$ & $89(40-104)$ \\
\hline Interval (h) & $4.3(3.7-5.3)$ & $4.5(4.2-5.0)$ & $10.4(4.5-13.3)^{*}$ & - \\
\hline Equivalent $4 \mathrm{~h}$ concentration & $51(26-83)$ & $136(118-168)^{*}$ & $269(242-407)^{*}$ & - \\
\hline Ethanol co-ingestion & $18(64.3 \%)$ & $11(61.1 \%)$ & $8(40.0 \%)$ & $2(50.0 \%)$ \\
\hline Drug co-ingestion & $16(57.1 \%)$ & $4(22.2 \%)$ & $7(35.0 \%)$ & $2(50.0 \%)$ \\
\hline Serum creatinine $(\mu \mathrm{mol} / \mathrm{L})$ & $78(68-92)$ & $83(76-92)$ & $76(72-81)$ & $86(70-138)$ \\
\hline Acetylcysteine administered & $5(17.9 \%)$ & $10(55.6 \%)^{\dagger}$ & $17(85.0 \%)^{\dagger \dagger}$ & $2(50.0 \%)$ \\
\hline$\Delta$ creatinine $(\mu \mathrm{mol} / \mathrm{L})$ & $1(-6$ to 9$)$ & $-3(-4$ to -1$)$ & $-4(-10$ to -1$)$ & $-7(-)^{\ddagger}$ \\
\hline $\begin{array}{l}\Delta \text { creatinine }=\text { change from basel } \\
{ }^{*} p<0.001 \text { by Mann Whitney test } \\
\text { tp }<0.05 \\
{ }^{\dagger \dagger} p<0.001 \text { by Pearson's Chi squa } \\
+ \text { Unable to calculate interquartile }\end{array}$ & $\begin{array}{l}\text { after acetylcysteine } \\
\text { test compared to ' } m \\
\text { ge due to small sam }\end{array}$ & $\begin{array}{l}\text { nor' group. } \\
\text { le. }\end{array}$ & & \\
\hline
\end{tabular}

Table 2: Urine Assay Data as Median (Interquartile Range)

\begin{tabular}{lcccc}
\hline & \multicolumn{3}{c}{ Acute single ingestion } & \\
\cline { 2 - 4 } & Minor & Moderate & Severe & Staggered overdose \\
\hline Laboratory assays & $\mathrm{n}=24$ & $\mathrm{n}=17$ & $\mathrm{n}=19$ & $\mathrm{n}=3$ \\
\hline Albumin (mg/L) & $8(0-12)$ & $12(5-25)$ & $11(6-22)$ & $33(19-38)$ \\
\hline Creatinine (mmol/L) & $6(3-10)$ & $7(3-12)$ & $8(5-11)$ & $4(3-17)$ \\
\hline Total protein (mg/L) & $90(50-183)$ & $70(40-130)$ & $110(75-205)$ & $150(125-345)$ \\
\hline ACR & $0(0-2.4)$ & $1.4(0-2.5)$ & $1.3(0.8-3.0)$ & $2.5(2.0-5.9)$ \\
\hline Near-patient assays & $\mathrm{n}=27$ & $\mathrm{n}=19$ & $\mathrm{n}=20$ & $\mathrm{n}=4$ \\
\hline Albumin (mg/L) & $10(10-30)$ & $10(10-55)$ & $30(5-80)$ & $55(25-98)$ \\
\hline Creatinine (mmol/L) & $4(1-9)$ & $4(3-9)$ & $4(3-9)$ & $9(1-20)$ \\
\hline ACR $=$ albumin:creatinine ratio. & & & \\
\hline
\end{tabular}

and others (7). Acetylcysteine was administered to 33 patients (47.1\%). Baseline clinical and laboratory data are presented according to the extent of acetaminophen exposure (Table 1).

Data from near-patient testing were available for all subjects $(\mathrm{n}=70)$, whereas laboratory data were available for 63 subjects. The discrepancy was due to samples arriving in the laboratory too late to allow analysis ( $>12$ hours) in 5 cases, and samples lost during transport to the laboratory in 2 cases. Urinary albumin, creatinine, total protein, and albumin:creatinine ratio values were similar across minor, moderate, and severe acetaminophen exposure groups (Table 2). Near-patient tests were significantly more sensitive than laboratory assays for both albumin $>20 \mathrm{mg} / \mathrm{L}$ $(p=0.007)$ and albumin:creatinine ratio $>3.0 \mathrm{mg} / \mathrm{mmol}(p=$ 0.039) (Table 3). 
Table 3: Abnormal Albumin and Albumin: Creatinine Ratio (ACR) Values Compared between Severity of Acetaminophen Exposure (Chi-Square Trend Tests) and between Assays $(\mathrm{N}=63)$

\begin{tabular}{|c|c|c|c|c|c|c|c|}
\hline & \multicolumn{3}{|c|}{ Acute single ingestion } & \multirow[b]{2}{*}{ Chi-square trend test } & \multirow[b]{2}{*}{$\begin{array}{l}\text { Staggered } \\
\qquad \mathbf{n}=\mathbf{3}\end{array}$} & \multirow[b]{2}{*}{$\begin{array}{l}\text { All patients } \\
n=63\end{array}$} & \multirow[b]{2}{*}{$\begin{array}{l}\text { Between-assay } \\
\text { Chi-square test }\end{array}$} \\
\hline & $\begin{array}{l}\text { Minor } \\
\mathbf{n}=\mathbf{2 4}\end{array}$ & $\begin{array}{l}\text { Moderate } \\
n=17\end{array}$ & $\begin{array}{l}\text { Severe } \\
n=19\end{array}$ & & & & \\
\hline \multicolumn{8}{|c|}{ Albumin $>20 \mathrm{mg} / \mathrm{L}$} \\
\hline Laboratory assay & $5(20.8 \%)$ & $6(35.3 \%)$ & $5(26.3 \%)$ & $\chi^{2}=0.21 p=0.644$ & $2(66.7 \%)$ & $18(28.1 \%)$ & \\
\hline Near-patient test & $10(41.7 \%)$ & $8(47.1 \%)$ & $14(73.7 \%)$ & $\chi^{2}=4.19 p=0.041$ & $2(66.7 \%)$ & $34(53.1 \%)$ & $\chi^{2}=7.37 p=0.007$ \\
\hline \multicolumn{8}{|c|}{ ACR $>3.0 \mathrm{mg} / \mathrm{mmol}$} \\
\hline Laboratory assay & $5(20.8 \%)$ & $4(23.5 \%)$ & $6(31.6 \%)$ & $\chi^{2}=0.63 p=0.426$ & $1(33.3 \%)$ & $16(25.0 \%)$ & \\
\hline Near-patient test & $7(29.2 \%)$ & $7(41.2 \%)$ & $13(68.4 \%)$ & $\chi^{2}=6.46 p=0.011$ & $1(33.3 \%)$ & $28(43.8 \%)$ & $\chi^{2}=4.23 p=0.039$ \\
\hline
\end{tabular}

No significant relationship was found between the extent of acetaminophen exposure and laboratory determination of albumin. Receiver operating characteristic (ROC) analyses for equivalent 4-hour acetaminophen concentration and albumin $>20 \mathrm{mg} / \mathrm{L}$ gave area under curve $=57.9 \%$ (95\% confidence interval $44.4-70.5 \%$ ), and for albumin: creatinine ratio $>3.0 \mathrm{mg} / \mathrm{mmol}$ gave area under curve $=51.0 \%$ (95\% confidence interval 37.7-64.1\%). In contrast, a positive relationship was found between the extent of acetaminophen exposure and near-patient measures of albuminuria $(p=0.041)$ and abnormal albumin:creatinine ratio $(p=$ 0.011) (Table 3). Receiver operating characteristic (ROC) analyses showed that equivalent 4-hour acetaminophen concentrations $>111 \mathrm{~g} / \mathrm{L}$ were predictive of near-patient positive tests for albuminuria (area under ROC curve $=65.0 \%, 95 \%$ confidence interval $52.3-76.3 \%$ ) and $>119 \mathrm{~g} / \mathrm{L}$ were predictive of an abnormal albumin:creatinine ratio (area under ROC curve $=67.5 \%, 95 \%$ confidence interval 54.8-78.5\%).

None of the patients developed acute renal failure. There was no relationship between the extent of acetaminophen exposure and the change from baseline creatinine concentration in patients who received acetylcysteine.

\section{DISCUSSION}

The present study found no relationship between the extent of acetaminophen exposure and urinary protein excretion. The occurrence of microalbuminuria was similar between patients who had been exposed to a broad range of different acetaminophen concentrations in a potentially toxic range. These data demonstrate that a dose-dependent effect on urinary protein excretion after deliberate acetaminophen overdose is lacking. This is in contrast to data that show a relationship between exposure to high acetaminophen concentrations and proteinuria in animals. Whereas the risk of hepatotoxicity after acetaminophen overdose correlates with the extent of drug exposure, such a relationship might not exist for nephrotoxicity. Development of renal impairment might be determined by factors apart from the extent of acetaminophen exposure, e.g., dehydration, staggered ingestion, preexisting renal insufficiency, and chronic excess ethanol consumption $[5,6]$.

Acetaminophen is capable of inducing hepatic and renal injury by distinct pathological mechanisms, and the development of renal failure is unrelated to the presence or severity of acetaminophen-induced liver injury $[3,5]$. Glutathione depletion is an important mechanism in hepatotoxicity, and early acetylcysteine administration minimizes the risk of developing acetaminophen-induced hepatotoxicity. In contrast, glutathione depletion in the kidney is unrelated to the extent of nephrotoxicity, and acetylcysteine administration affords little or no protection against development of nephrotoxicity [3, 16-18]. Specific mechanisms of acetaminophen-induced renal injury have been proposed, including caspase activation, altered regulation of apoptosis [19,20], oxidative stress [21], and activation of cyclooxygenase and microsomal monooxygenase pathways within the kidney $[18,22,23]$. Liver-derived glutathione conjugates of acetaminophen metabolites may evoke nephrotoxicity by covalently binding to renal macromolecules [24,25], and might contribute to acute renal failure in certain patients exposed to large quantities of acetaminophen [26,27].

A discrepancy was noted between the different analytical methods of urinary albumin determination. Near-patient testing was overly sensitive for albumin detection, and showed a positive relationship between acetaminophen exposure and albumin excretion that was not confirmed by laboratory measurement. This disparity indicates that Microalbustix data are confounded in an acetaminophen exposure-dependent manner, suggesting interference by another moiety, e.g., acetaminophen, acetylcysteine, or a renally excreted metabolite. The clinical relevance of this finding is uncertain, but suggests that near-patient testing for urinary albumin might be unreliable in this patient group.

An important limitation is that none of the patients developed acute renal failure. Lack of a relationship between proteinuria and acetaminophen exposure does not diminish the possibility that proteinuria might predict development of nephrotoxicity in susceptible individuals. This hypothesis would require evaluation 
in a substantially larger population to include sufficient numbers that develop significant nephrotoxicity. Based on nephrotoxicity in around $0.6 \%$ of patients in this institution, at least 273 patients would need to be studied to allow detection of nephrotoxicity (90\% power, 0.05 alpha level). Despite this study limitation, the numbers of patients included were sufficient to allow urinary protein excretion to be examined across a broad range of acetaminophen exposures. A potential limitation is that albuminuria is insufficiently sensitive to detect renal impairment. Raised urinary a-1-microglobulin and cystatin C concentrations may allow earlier detection of acute tubular necrosis [28]. The potential role of these urinary markers and the use of novel biomarkers of renal function need further study in this high-risk patient group.

In conclusion, the extent of acetaminophen exposure after deliberate overdose is unrelated to urinary albumin and protein excretion. Further work is required to determine whether microalbuminuria or other novel biomarkers might allow prediction of acute renal failure after acetaminophen overdose.

This work was supported by a Medical Fellowship from GlaxoSmithKline UK Limited (A0704117).

\section{REFERENCES}

1. Waring WS, Jamie H, Leggett GE. Delayed onset of acute renal failure after significant paracetamol overdose: a case series. Hum Exp Toxicol [in press]

2. Boutis K, Shannon M. Nephrotoxicity after acute severe acetaminophen poisoning in adolescents. J Toxicol/Clin Toxicol 2001;39:441-445.

3. Eguia L, Materson BJ. Acetaminophen-related acute renal failure without fulminant liver failure. Pharmacotherapy 1997; 17:363-370.

4. Kleinman JG, Breitenfield RV, Roth DA. Acute renal failure associated with acetaminophen ingestion: report of a case and review of the literature. Clin Nephrol 1980;14:201-205.

5. von Mach MA, Hermanns-Clausen M, Koch I, Hengstler JG, Lauterbach M, Kaes J et al. Experiences of a poison center network with renal insufficiency in acetaminophen overdose: an analysis of 17 cases. Clin Toxicol 2005;43:31-37.

6. Bray GP, Mowat C, Muir DF, Tredger JM, Williams R. The effect of chronic alcohol intake on prognosis and outcome in paracetamol overdose. Hum Exp Toxicol 1991;10:435-438.

7. Mour G, Feinfeld DA, Caraccio T, McGuigan M. Acute renal dysfunction in acetaminophen poisoning. Ren Fail 2005;27:381-383.

8. Bellomo R, Ronco C, Kellum JA, Mehta RL, Palevsky P. Acute renal failure: definition, outcome measures, animal models, fluid therapy and information technology needs: the second international consensus conference of the Acute Dialysis Quality Initiative (ADQI) Group. Crit Care 2004;8:R204-212.
9. Coca SG, Yalavarthy R, Concato J, Parikh CR. Biomarkers for the diagnosis and risk stratification of acute kidney injury: A systematic review. Kidney Int 2008;73:1008-1016.

10. Mitić-Zlatković M, Stefanović V. Acute effects of acetaminophen on renal function and urinary excretion of some proteins and enzymes in patients with kidney disease. Ren Fail 1999; 21: 525-532.

11. Kocaoğlu S, Karan A, Berkan T, Başdemir G. Acute acetaminophen nephrotoxicity and urinary gamma-glutamyl transferase activity in rats. Drug Metabol Drug Interact 1997;14:47-54.

12. Bernard AM, de Russis R, Amor AO, Lauwerys RR. Potentiation of cadmium nephrotoxicity by acetaminophen. Arch Toxicol 1988;62:291-294.

13. Buckley N, Eddleston M. Paracetamol (acetaminophen) poisoning. Clin Evid 2005;14:1738-1744.

14. Redon J, Morales-Olivas F, Galgo A, Brito MA, Mediavilla J, Marín R et al. Urinary albumin excretion and glomerular filtration rate across the spectrum of glucose abnormalities in essential hypertension. J Am Soc Nephrol 2006;17(12 Suppl 3): S236-245.

15. Waring WS, Robinson OD, Stephen AF, Dow MA, Pettie JM. Does the patient history predict hepatotoxicity after acute paracetamol overdose. QJM 2008;101:121-125.

16. Jones AF, Vale JA. Paracetamol poisoning and the kidney. J Clin Pharm Ther 1993;18: 5-8.

17. Slitt AL, Dominick PK, Roberts JC, Cohen SD. Standard of care may not protect against acetaminophen-induced nephrotoxicity. Basic Clin Pharmacol Toxicol 2004;95: 247-248.

18. Möller-Hartmann W, Siegers CP. Nephrotoxicity of paracetamol in the rat-mechanistic and therapeutic aspects. J Appl Toxicol 1991;11:141-146.

19. Lorz C, Justo P, Sanz A, Subirá D, Egido J, Ortiz A. Paracetamol-induced renal tubular injury: a role for ER stress. J Am Soc Nephrol 2004;15:380-389.

20. Lorz C, Justo P, Sanz AB, Egido J, Ortíz A. Role of Bcl-xL in paracetamol-induced tubular epithelial cell death. Kidney Int 2005;67:592-601.

21. Isik B, Bayrak R, Akcay A, Sogut S. Erdosteine against acetaminophen induced renal toxicity. Mol Cell Biochem 2006;287:185-191.

22. Younes M, Sause C, Siegers CP, Lemoine R. Effect of deferrioxamine and diethyldithiocarbamate on paracetamol-induced hepato- and nephrotoxicity. The role of lipid peroxidation. J Appl Toxicol 1988;8:261-265.

23. Waring WS, Stephen AF, Malkowska AM, Robinson OD. Acute acetaminophen overdose is associated with dose-dependent hypokalaemia: a prospective study of 331 patients. Basic Clin Pharmacol Toxicol 2008;102:325-328.

24. Kim YC, Yim HK, Jung YS, Park JH, Kim SY. Hepatic injury induces contrasting response in liver and kidney to chemicals that are metabolically activated: role of male sex hormone. Toxicol Appl Pharmacol 2007;223:56-65. 
25. Trumper L, Monasterolo LA, Elías MM. Nephrotoxicity of acetaminophen in male Wistar rats: role of hepatically derived metabolites. J Pharmacol Exp Ther 1996;279:

548-554.

26. Abraham P, Kanakasabapathy I, Dian BJ. Propylthiouracil attenuates acetaminophen-induced renal damage in the rat. Nephrology 2005;10:588-593.
27. Yamada T, Ludwig S, Kuhlenkamp J, Kaplowitz N. Direct protection against acetaminophen hepatotoxicity by propylthiouracil. J Clin Invest 1981;67:688-695.

28. Herget-Rosenthal S, Poppen D, Hüsing J, Marggraf G, Pietruck F, Jakob HG et al. Prognostic value of tubular proteinuria and enzymuria in nonoliguric acute tubular necrosis. Clin Chem 2004;50:552-528. 